\title{
Carcass characteristics, muscle composition and meat quality of halothane positive and halothane negative Pietrain boars
}

\author{
J. BOUSSET, B.L. DUMONT
}

I.N.R.A., Laboratoire de Recherches sur la Viande, 78350 Jouy-en-Josas

Carcass composition and conformation and the main physico-chemical traits (amounts of hacm iron, sarcoplasmic protein nitrogen, soluble nitrogen, total nitrogen, frequency of iso 5 LDH. pH, water holding capacity) of four muscles (M. Adductor, Biceps femoris, Semimembranosus, Longissimus dorsi, at two levels for the latter) were studied in two groups of five halothane positive (HP) and five halothane negative (HN) young boars of the Pietrain breed (8-month old and about $100 \mathrm{~kg}$ live weight).

The analysis made with the multivariate method of centered data suggested a close relationship between the HP condition and carcass fleshiness. Nevertheless, among $\mathrm{HP}^{\mathrm{P}}$ carcasses there was a large variation for all the chemical characteristics. The Longissimus dorsi was the most affected muscle by the HP condition.

The discriminant function allowed to separate the two groups from each trait considered on the five muscle samples. The HP condition seemed to be associated with a decrease in haem iron and sarcoplasmic protein content an increase in iso $5 \mathrm{LDH}$ and a lesser water holding capacity. In each animal, the effect of the HP condition was, more or less marked according to muscles and for the same type of muscle, was different between animais.

\section{Comparative study of pork lipids according to carcass locations}

\author{
G. GANDEMER, N. SHARMA, Michèle VIAU \\ I.N.R.A., Laboratoire des Aliments d'Origine Animale, \\ rue de la Géraudière, 44072 Nantes Cedex
}

This study was conducted to determine the relative amounts of total, neutral and polar intramuscular lipids as well as the composition of these three fractions in Longissimus dorsi (L.D.), Transversus abdominis (T.A) and Biceps femoris (B.F.) at different carcass locations (5th dorsal and 2nd lumbar position of the L.D. muscle) from left and right sides of six pig carcasses. The following conclusions were drawn :

1) There was no significant difference between left and right sides of the same animal in terms of lipid content and fatty acid composition.

2) In our experimental conditions three muscles showed no significant difference between total $(2.4$ to $2.8 \mathrm{~g} / 100 \mathrm{~g})$ and neutral lipid $(1.4$ to $2.1 \mathrm{~g} / 100 \mathrm{~g})$ content. However, significant differences were observed in total and neutral lipid contents of L.D. at the 5th dorsal $(2.7$ and $2.1 \mathrm{~g} / 100 \mathrm{~g})$ and 2 nd lumbar rib $(2.1$ and $1.4 \mathrm{~g} / 100 \mathrm{~g})$, respectively.

3) Polar lipid contents were significantly different within the selected muscles; L.D., B.F. and T.A. contained $0.65,0.84$ and $0.97 \mathrm{~g} / 100 \mathrm{~g}$ muscle, respectively.

4) Fatty acid composition of neutral lipids was influenced by the muscle studied, but no between-muscle difference was observed in the fatty acid composition of polar lipids.

5) Intramuscular lipids contained essential fatty acids of family n-6 $(0.4$ p. 100 of fresh weight). Phospholipids were the most PUFA rich, containing all the long chains (20-22 C) important for dietary requirements. 